\title{
EDUCAÇÃO CORPORATIVA E SUA IMPORTANCIA NAS FÁBRICAS DE SOFTWARE DO SUDOESTE DO PARANÁ
}

Ana Paula Thiesen ${ }^{1}$

RESUMO: A falta de capacitação profissional no atual cenário do mercado de trabalho é uma grande preocupação encontrada junto a todos os gestores que buscam crescimento junto a empresa e diante aos seus demais concorrentes e com isso a proposta de métodos de educação corporativa acabam sendo uma forma econômica e lucrativa de se gerar tais profissionais. Este estudo tem como objetivo elencar e mostrar de forma clara quais são os métodos de implementação das universidades corporativas, bem como os níveis de satisfação encontrado em algumas empresas onde os métodos já foram devidamente aplicados e estão em funcionamento.

Palavras-chave: Educação corporativa, satisfação, capacitação.

\section{CORPORATE EDUCATION AND ITS IMPORTANCE IN SOUTHWEST SOFTWARE FACTORS IN PARANÁ}

\begin{abstract}
The lack of professional training in the current labor market scenario is a major concern found among all managers who seek growth with the company and its other competitors and with this the proposal of methods of corporate education end up being an economic and to generate such professionals. This study aims to clearly identify and describe the methods of implementation of corporate universities, as well as the levels of satisfaction found in some companies where the methods have already been properly applied and are in operation.
\end{abstract}

Keywords: Corporate education, satisfaction, training.

\section{Introdução}

A capacitação profissional dos trabalhadores atualmente é algo que vem sendo um preocupante perante as empresas e seus gestores. Devido a não receberem uma educação básica adequada e em alguns casos, tendo até mesmo uma graduação insatisfatória, os mesmos profissionais saem se dizendo aptos para o mercado, enquanto no exercício de suas atividades não se mostram tão capazes.

Para que esse gargalo profissional seja suprido, muita destas empresas, que necessitam de mão de obra especifica e de qualidade, estão instituindo o método de educação e universidade corporativa, por meio de técnicas já aprovadas para que assim possam internamente capacitar o profissional e assim o preparar adequadamente para os desafios empresariais a serem enfrentados.

Esta prática que se torna uma grande crescente no mercado corporativo vem como um atrativo de baixo custo e maior assertividade, assim conseguindo chegar a níveis significativos de ganhos caso seja implementada de forma adequada. Neste trabalho espera-se abordar e explanar de forma simples e objetiva os conceitos sobre educação corporativa e sua atual importância para o mercado de trabalho, além de seu impacto sobre o desempenho de seus funcionários.

\footnotetext{
1 Bacharel em ciência contábeis pela Unisep - União de Ensino do Sudoeste do Paraná, pós-graduada em Contabilidade, Perícia e Auditoria pela UNOPAR - Universidade Norte do Paraná e pós-graduada em MBA Gestão Estratégica pela FAE Business School.
} 
A pesquisa executada como proposta do trabalho tem como objetivo mostrar quais são os níveis de satisfação com a implementação dos métodos de educação corporativa, bem como as razões para as respostas encontradas, para que assim possa servir de base para outros gestores executarem suas próprias adaptações da prática, conseguindo ajustar da melhor forma para a empresa.

\section{Fundamentação Teórica}

A troca de paradigmas da gestão empresarial, passando dos conceitos fordistas e tayloristas, indo de encontro a uma gestão flexível fez com que empresas que buscam seu crescimento e desenvolvimento contínuo deem mais ênfase a um setor que anteriormente era pouco abordada: a educação.

Neste momento de mudanças em que as empresas passam a ter sua estrutura descentralizada e geram um modelo de interdependência, onde necessitam que as pessoas tenham o conhecimento não somente da sua atividade, mas também num âmbito geral, para que possa tomar decisões simultaneamente na execução de suas atividades, o foco e a exigência tida sobre o recurso humano dentro da organização se torna muito maior. Com esta exigência junto às pessoas, criou-se outra necessidade: a aprendizagem contínua.

Para que exista o desenvolvimento de tais conhecimentos e demais habilidades não intrínsecas às pessoas, as organizações passam a buscar meios de introduzir esse aprendizado de forma direcionada dentro do próprio ambiente de trabalho, uma vez em que estas mesmas pessoas nem sempre conseguem ter estas habilidades adquiridas em suas formações básicas oferecidas governamentalmente, e é neste contexto em que a educação corporativa aliada à gestão de pessoas entra como fator decisivo agindo em paralelo e concomitantemente.

Buscando não somente o desenvolvimento do conhecimento, a gestão de pessoas passa a ter o papel de selecionar, motivar, desenvolver e manter os profissionais mais talentosos na organização, e trazendo a educação corporativa, visa um sistema de desenvolvimento das habilidades, atitudes e posturas do profissional.

\section{Definição de Educação Corporativa/Universidade Corporativa}

O termo educação corporativa ou universidade corporativa surgiu ao ser abordado por MEISTER em seu livro "Educação corporativa: a gestão do capital intelectual por meio das universidades corporativa" em 1999 e em seguida abordada na defesa de doutorado de Marisa Éboli em 2004. Anteriormente o emprego dos conceitos já era feito nos Estados Unidos desde os anos 1950 em empresas que buscavam melhorar os conhecimentos de seus funcionários. 
Conforme define Meister (1999, p.35), universidade é um "guarda-chuva estratégico para desenvolver e educar funcionários, clientes, fornecedores e comunidade, a fim de cumprir as estratégias da organização".

Nesta forma de ensino diferenciado, o espaço físico é levado para um ambiente conceitual e não exatamente real, pois com ele vem uma flexibilização do modo de repasse de conhecimento, não sendo necessário que seja realmente presencial, sendo difundido ao modo à distância ou semipresencial, conseguindo ser acompanhado por meios virtuais e permitindo que o educando/funcionário escolha o melhor momento para estar recebendo tal conhecimento, conforme abordam Blois e Melca (2005).

Com esta forma de repasse de informação, a gestão de pessoas pode realmente empregar os conceitos fundamentais sobre a remuneração por competências, conforme já abordado anteriormente, e repassando ao funcionário as possibilidades de crescimento interno na empresa, lhe dando incentivo de crescimento.

Meister (1999) analisa que as implantações de projetos voltados a universidades corporativas tendem a abranger alguns princípios. São eles:

- Desenho de programas que incorporem a identificação das competências criticas;

- Migração do modelo "sala de aula" para múltiplas formas de aprendizagem aprendizagem a qualquer hora e lugar;

- Delineamento de programas que reflitam o compromisso da empresa com a cidadania empresarial;

- Estímulo para gerentes e líderes se envolverem com o processo de educação;

- Criação de sistemas eficazes de avaliação dos investimentos e resultados obtidos.

Já o conceito de universidade corporativa corresponde à aplicação de alguns pressupostos, elencados a seguir:

- Objetivo Principal: desenvolver as competências críticas do negócio em vez de habilidades individuais;

- Foco do Aprendizado: privilegiar o aprendizado organizacional fortalecendo a cultura corporativa e o conhecimento coletivo, e não apenas o conhecimento individual;

- Escopo: concentra-se nas necessidades dos negócios, tornando o escopo estratégico, e não focado exclusivamente nas necessidades individuais;

- Ênfase dos programas: conceber e desenhar ações e programas educacionais a partir de estratégias de negócios, ou seja, da identificação das competências críticas empresariais. 
- Público alvo: adotar o conceito de educação inclusiva, desenvolvendo competências críticas no público interno e externo (familiares, clientes, fornecedores, distribuidores, parceiros comerciais e comunidade), e não somente nos funcionários.

- Local: contemplar a possibilidade de ser um projeto virtual e não necessariamente um local físico;

- Resultado: aumentar a competitividade empresarial e não apenas o aumento de habilidades individuais.

Com base nesse processo de implementação é possível já se ter a adoção do conceito de universidade corporativa dentro da empresa, assim permitindo que a mesma analise melhor seus profissionais potenciais e crie por fim um plano de desenvolvimento de talentos humanos, tornando a mesma mais competitiva perante o mercado.

\section{Princípios de Sucesso de um Plano Estratégico de Educação Corporativa}

Para que se possa definir os princípios que trarão sucesso a implementação de educação corporativa, Éboni (2004) diferencia os conceitos de princípios e práticas, onde os define da seguinte forma:

- Princípios: são as bases filosóficas e os fundamentos que norteiam uma ação, ou seja, são os elementos qualitativos conceituais predominantes na constituição de um Sistema de Educação Corporativa bem-sucedido.

- Práticas: são as escolhas organizacionais que propiciam transformar as escolhas estratégicas (competências empresariais) em escolhas pessoais (competências humanas).

E com isso a mesma conseguiu separar este processo em sete princípios, conforme descritos a seguir:

- Competitividade: Valorizar a educação como forma de desenvolver o capital intelectual dos colaboradores transformando-os efetivamente em fator de diferenciação da empresa frente aos concorrentes, para ampliar e consolidar sua capacidade de competir, aumentando assim seu valor de mercado por meio do aumento do valor das pessoas. Significa buscar continuamente elevar o patamar de competitividade empresarial por meio da instalação, desenvolvimento e consolidação das competências críticas - empresariais e humanas.

- Perpetuidade: Entender a educação não apenas como um processo de desenvolvimento e realização do potencial intelectual, físico, espiritual, estético e afetivo existente em cada colaborador mas também como um processo de transmissão da herança cultural, que exerce influência intencional e sistemática com o propósito de formação de um modelo mental, a fim 
de conservar, transmitir, disseminar, reproduzir ou até mesmo transformar as crenças e valores organizacionais, para perpetuar a existência da empresa.

- Conectividade: Privilegiar a construção social do conhecimento estabelecendo conexões, intensificando a comunicação empresarial e favorecendo a interação de forma dinâmica para ampliar a quantidade e qualidade da rede de relacionamentos com o público interno e externo (fornecedores, distribuidores, clientes, comunidade etc.) da organização que propiciem gerar, compartilhar e transferir os conhecimentos organizacionais considerados críticos para o negócio.

- Disponibilidade: Oferecer e disponibilizar atividades e recursos educacionais de fácil uso e acesso, propiciando condições favoráveis e concretas para que os colaboradores realizem a aprendizagem "a qualquer hora e em qualquer lugar", estimulando-os assim a se responsabilizarem pelo processo de aprendizado contínuo e autodesenvolvimento.

- Cidadania: Estimular o exercício da cidadania individual e corporativa e da construção social do conhecimento organizacional, por meio da formação de atores sociais, ou seja, sujeitos capazes de refletirem criticamente sobre a realidade organizacional, de construí-la e modificá-la continuamente, e de atuarem pautados por postura ética e socialmente responsável, imprimindo assim qualidade superior na relação de aprendizagem entre colaboradores, empresa e sua cadeia de agregação de valor.

- Parceria: Entender que desenvolver continuamente as competências críticas dos colaboradores, no intenso ritmo requerido atualmente no mundo dos negócios, é uma tarefa muito complexa e audaciosa, exigindo que se estabeleçam relações de parceria no âmbito interno e externo, com ideal e interesse comum na educação desses colaboradores.

○ Parcerias Internas: estabelecer relações de parceria com líderes e gestores, para que estes se envolvam e se responsabilizem pela educação e aprendizagem de suas equipes, e desempenhem plenamente o papel de educador, formador e orientador no cotidiano de trabalho para que sejam percebidos como lideranças educadoras, cujo modelo de comportamento deve ser seguido e buscado pelos demais colaboradores da empresa.

- Parcerias Externas: realizar parcerias com universidades, instituições de nível superior ou até mesmo clientes e fornecedores que tenham competência para agregar valor às ações e aos programas educacionais corporativos, ancoradas numa concepção comum sobre as necessidades de qualificação da força de trabalho.

- Sustentabilidade: Ser um centro gerador de resultados para e empresa, buscando agregar sempre valor ao negócio. Significa também buscar fontes alternativas de recursos que permitam um orçamento próprio e autossustentável, diminuindo assim as vulnerabilidades do 
projeto de Educação Corporativa, a fim de viabilizar um sistema de educação realmente contínuo, permanente e estratégico.

Vale salientar que a implementação assertiva de um sistema de educação corporativo depende dos ideais empregados pelos idealizadores do projeto e o quanto os mesmos estão ou não associados aos princípios abordados acima.

Deve também ser lembrado que cada principio não deve ser tratado como independente, pois todos formam uma estrutura interdependente e que o sucesso da implementação depende que todos os itens estejam devidamente satisfeitos.

\section{Metodologia}

A pesquisa foi caracterizada como de natureza aplicada. Em relação aos resultados, esta pesquisa é identificada como exploratória e estudo de caso. Quanto á abordagem, a pesquisa foi de caráter quantitativo/qualitativo. A pesquisa teve como objetivo mensurar o nível de contentamento e estimulo tido por funcionários de diversas empresas de software da cidade de Dois Vizinhos - PR, na realização de quaisquer que sejam as atividades relacionadas a educação corporativa. As mesmas foram escolhidas devido apresentarem programas de capacitação contínua, com diversas abordagens entre elas, assim conseguindo ter uma diferenciação entre os dados amostrados.

O universo dessa pesquisa foi uma parcela de empregados das diversas empresas, sendo divididas em amostras da seguinte magnitude:

- Empresa 1: 30 funcionários.

- Empresa 2: 10 funcionários.

- Empresa 3: 10 funcionários.

Totalizando uma quantia de 50 empregados, onde o objetivo era que todos respondam questionário sobre como se dá o processo de educação corporativa e qual o nível de satisfação do mesmo perante o modelo empregado na empresa. A fim de tabular estes dados, pesquisa foi implementada no período corrente do mês de junho/2017 nas três empresas abordadas, elencando em um questionário os níveis de satisfação e a disponibilidade apresentada por cada empregado para a realização efetiva de atividades de caráter educacional após o expediente de trabalho, além de uma questão extra onde o mesmo poderia elencar quais os pontos adequados ou não para a aplicação de tais medidas. 


\section{Apresentação e Análise dos Dados}

Conforme mencionado anteriormente, neste artigo tem-se a exemplificação de pesquisa feita com empregados de três empresas de software da cidade de Dois Vizinhos e para que se tenha um panorama completo dos dados analisados, as amostragens estão separadas por empresas, com os dados finais elencados posteriormente.

\section{Empresa 1}

Inicialmente, na Figura 1 estão sendo elencadas as áreas internas em que foram aplicadas as pesquisas referentes à Empresa 1.

FIGURA 1 - PESQUISAS APLICADAS POR SETOR DA EMPRESA

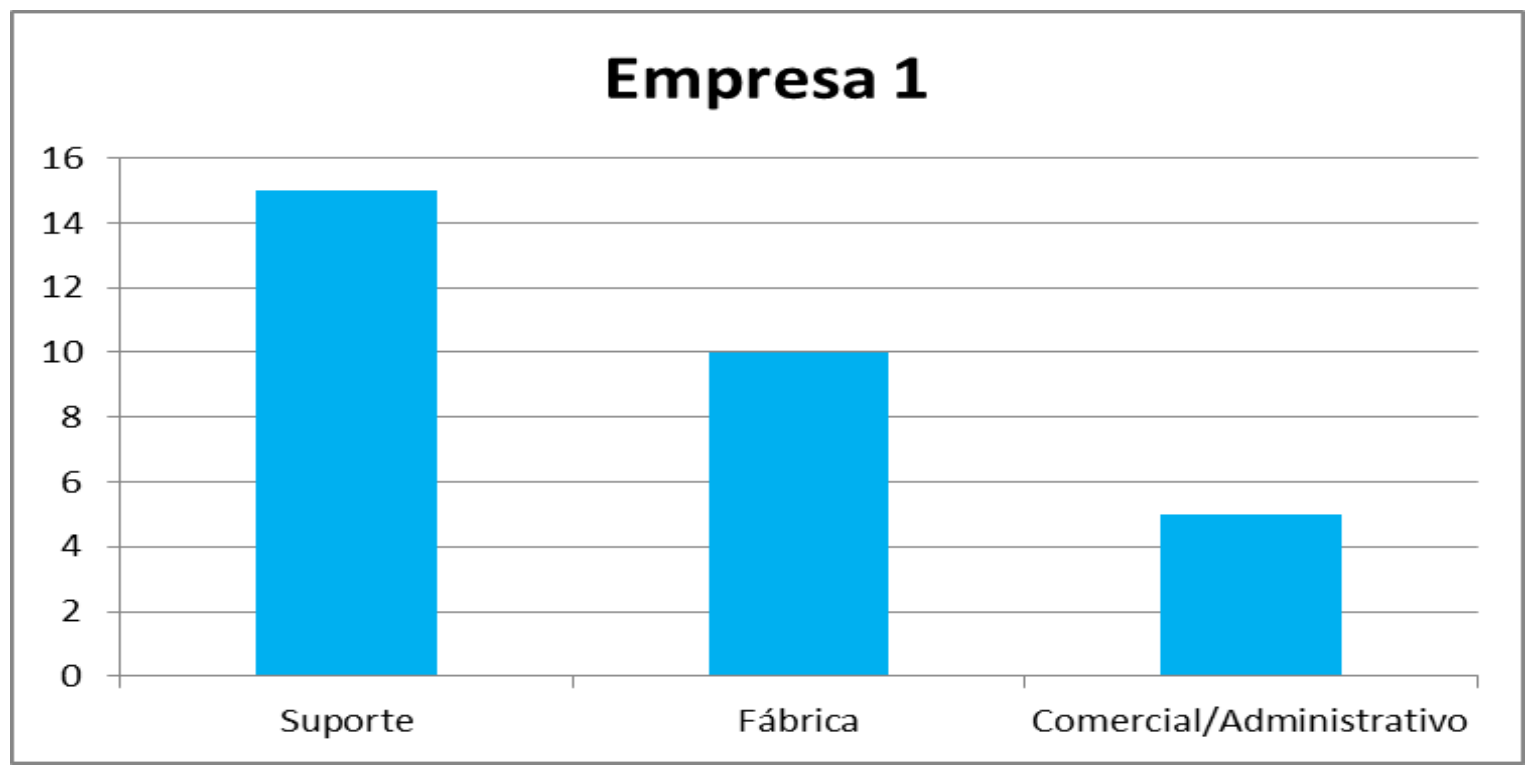

Fonte: Dados da pesquisa.

Conforme analisado nesta primeira amostra, os adeptos da pesquisa foram abrangentemente situados nas equipes de desenvolvimento (10 amostras) e suporte (15 amostras) da empresa, locais com maior quantidade de pessoas e necessidade de qualificações para o exercício de suas atividades e nos setores como comercial e administrativo, que já tem a sua mão de obra qualificada, a abrangência foi mais restrita com apenas 5 adeptos.

Já na Figura 2, esta apresentada a amostragem desta mesma empresa, porém quanto a satisfação dos planos de educação corporativa aplicada internamente. 
FIGURA 2 - NÍVEL DE SATISFAÇÃO ENTRE OS ENTREVISTADOS

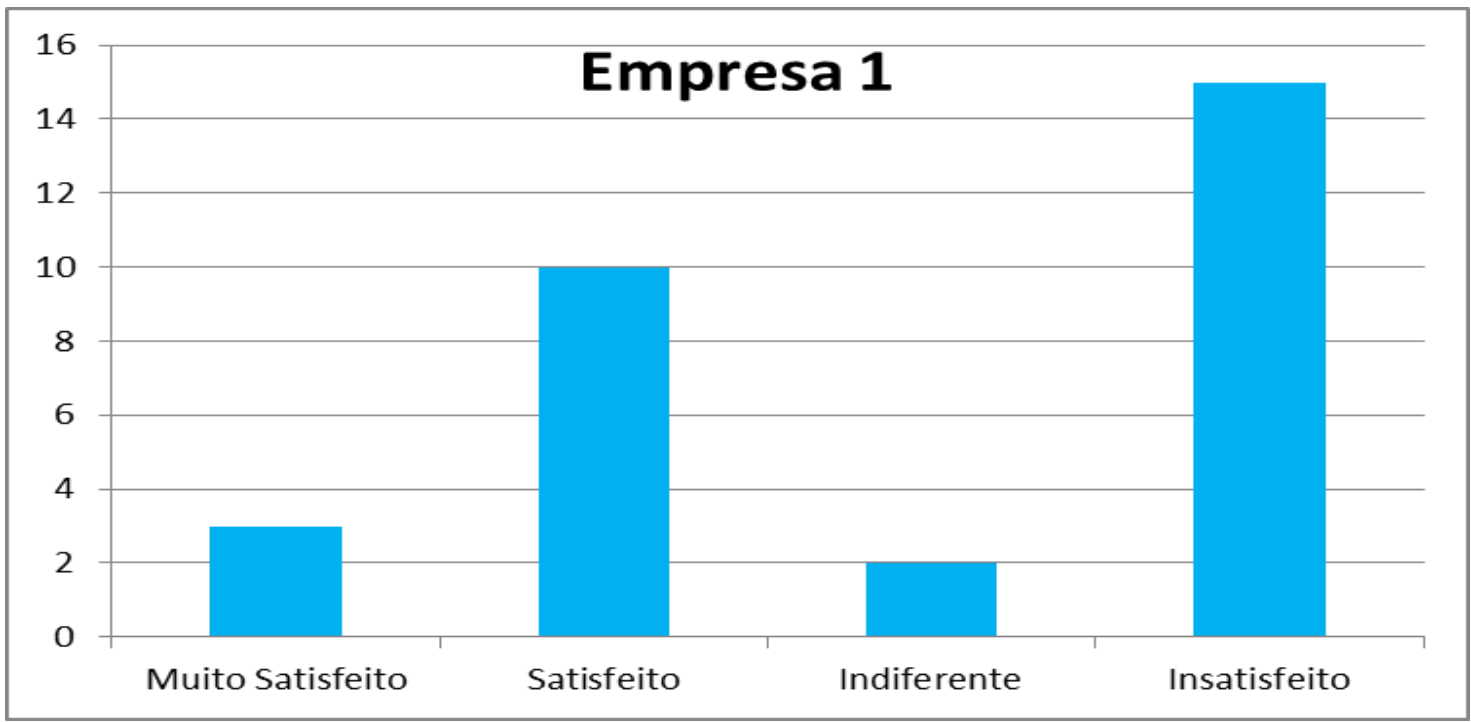

Fonte: Dados da pesquisa.

Com base nestes dados, pode-se analisar uma disparidade entre a satisfação encontrada entre os funcionários, onde as duas maiores quantidades estão entre os funcionários insatisfeitos (15 amostras) e os satisfeitos (10 amostras), sobrando assim uma parcela bem pouco significativa para os dois outros níveis: muito satisfeito ( 3 amostras) e indiferentes ( 2 amostras). Desta forma, se elencados em percentuais, observa-se que os índices de rejeição sobre o sistema de educação corporativa se tornam maiores que o índice de aprovação, conforme apresentado na Figura 3.

\section{FIGURA 3 - APROVAÇÃO DA POLITICA DE EDUCAÇÃO CORPORATIVA}

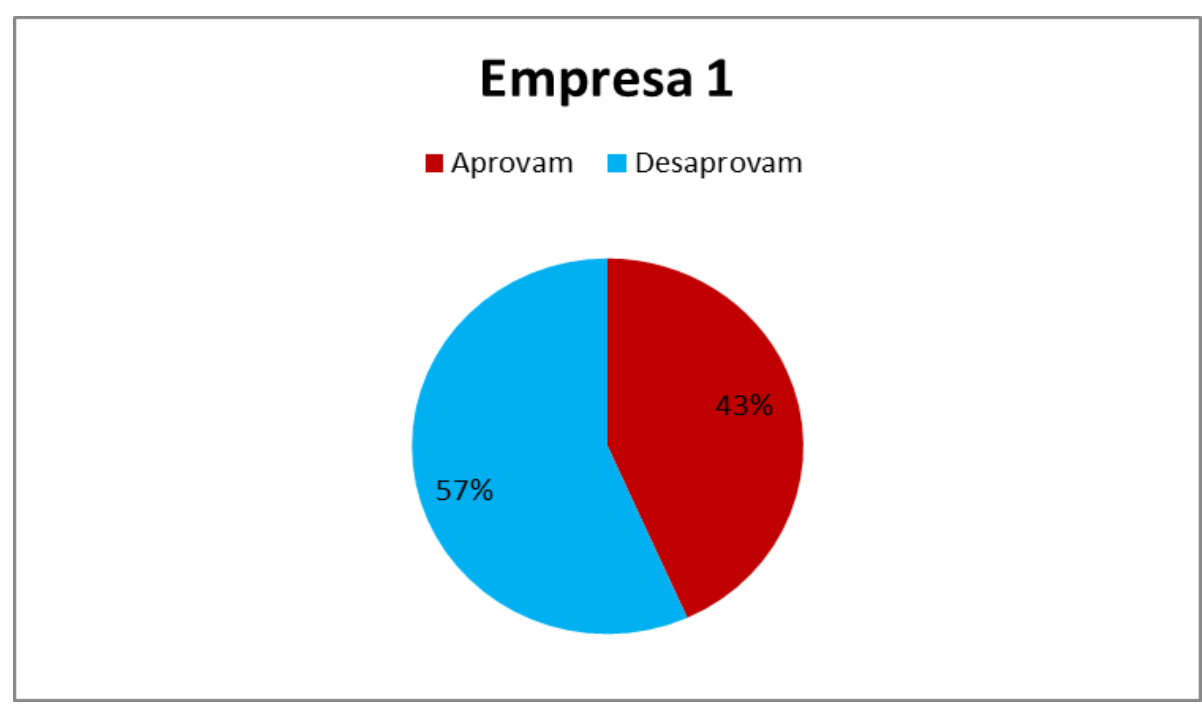

Fonte: Dados da pesquisa. 
Por fim, foi solicitado aos entrevistados que determinassem se após suas atividades corriqueiras do trabalho, ainda assim estaria disposto realizar alguma atividade de educação corporativa. Desta forma, na Figura 4 estão os índices elencados na pesquisa, sendo os mesmos equivalentes aos da Figura 3, onde os funcionários que aprovam são equivalentes os que estariam disponíveis para a realização de tais atividades, bem como os que desaprovam não estariam dispostos a execução das atividades.

\section{FIGURA 4 - DISPONIBILIDADE DE FUNCIONÁRIOS PARA QUALIFICAÇÃO EM EDUCAÇÃO CORPORATIVA}

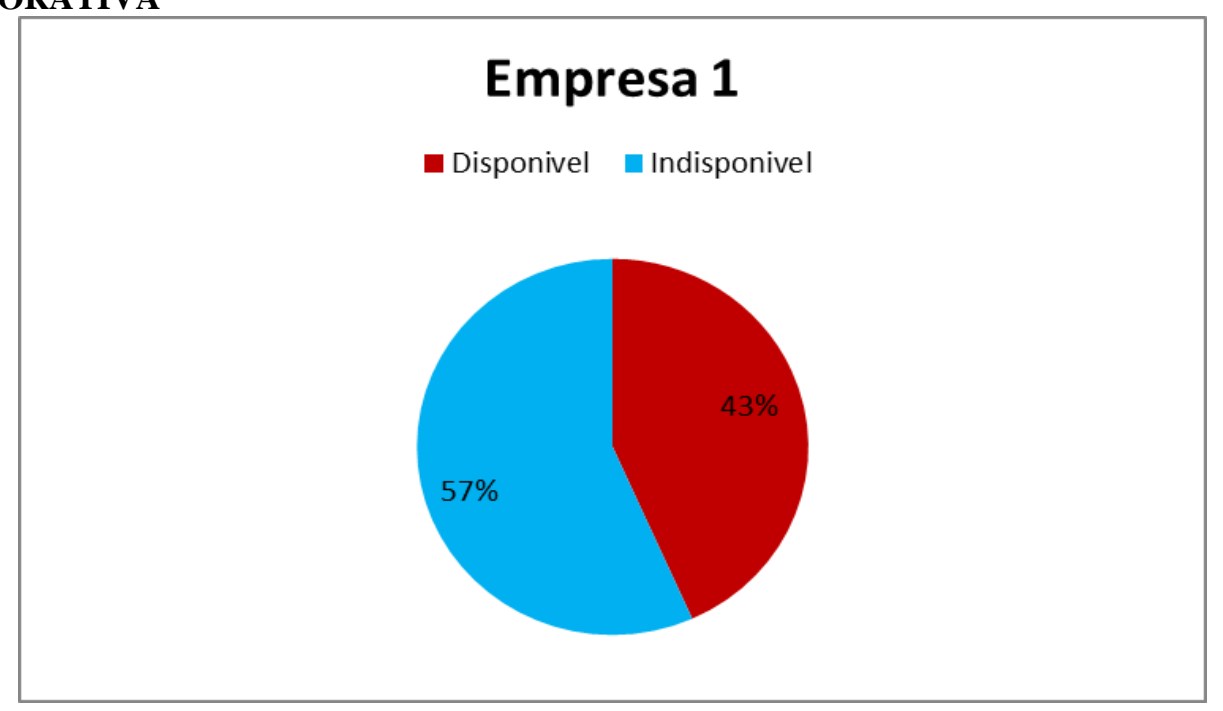

Fonte: Dados da pesquisa.

\section{Empresa 2}

Da mesma forma, conforme analisados os dados por setor da Empresa 2, estão dispostos na Figura 5.

\section{FIGURA 5 - PESQUISAS APLICADAS POR SETOR DA EMPRESA}

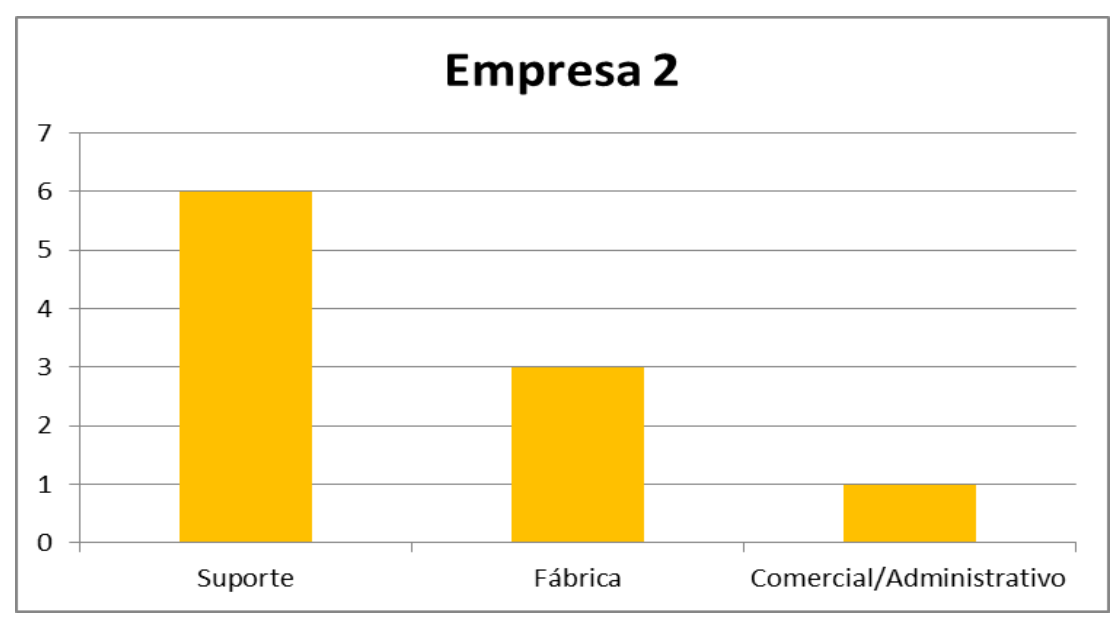

Fonte: Dados da pesquisa. 
Com a mesma constante da Empresa 1, na Empresa 2 os setores de desenvolvimento do produto tiveram sua maior participação na pesquisa (Suporte -7 amostras e Fábrica -3 amostras) e setores administrativos não optaram por sua participação (1 amostra).

Já ao analisar os dados pertinentes ao nível de satisfação, pode-se elencar como crescente para a satisfação dos dados analisados, onde 6 das amostras são de funcionários satisfeitos, 2 de funcionários muito satisfeitos e outras duas amostras de funcionários insatisfeitos, conforme Figura 6.

FIGURA 6 - NÍVEL DE SATISFAÇÃO ENTRE OS ENTREVISTADOS

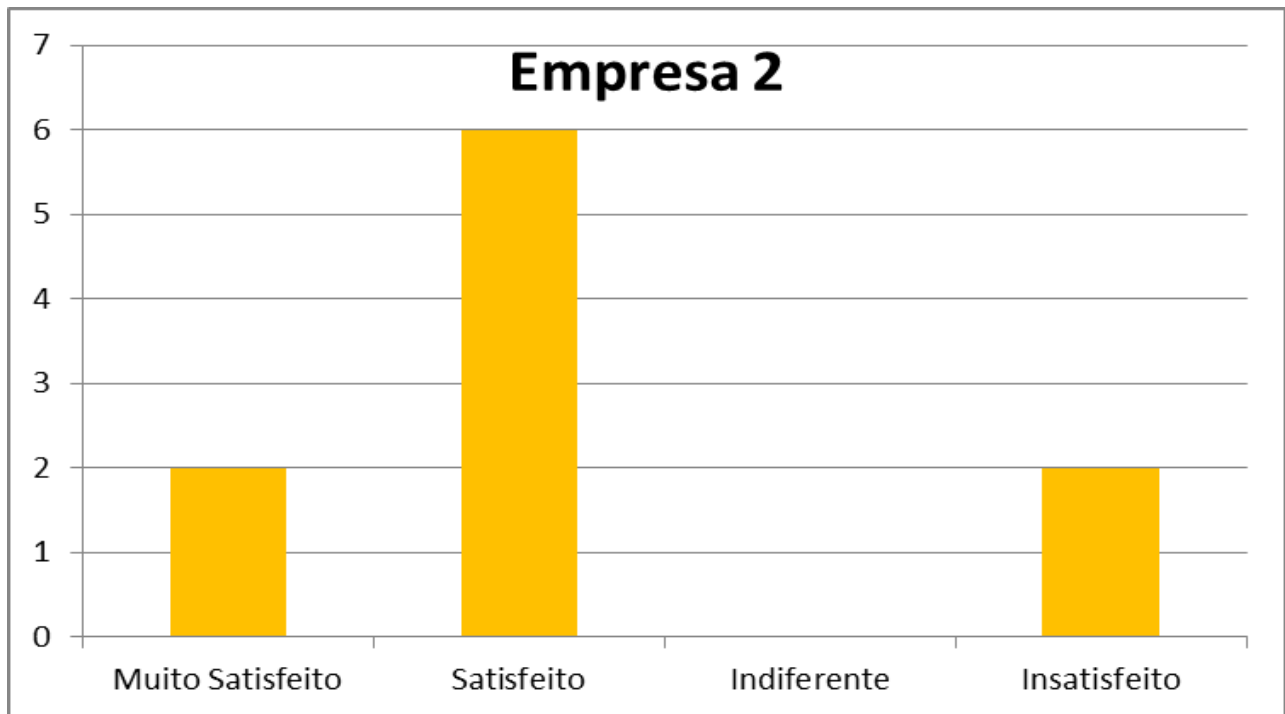

Fonte: Dados da pesquisa.

Para complementar os dados apresentados sobre a satisfação, na Figura 7 estão os dados apresentados em percentuais.

\section{GRÁFICO 7 - PERCENTUAIS DE APROVAÇÃo DA POLITICA DE EDUCAÇÃo CORPORATIVA}

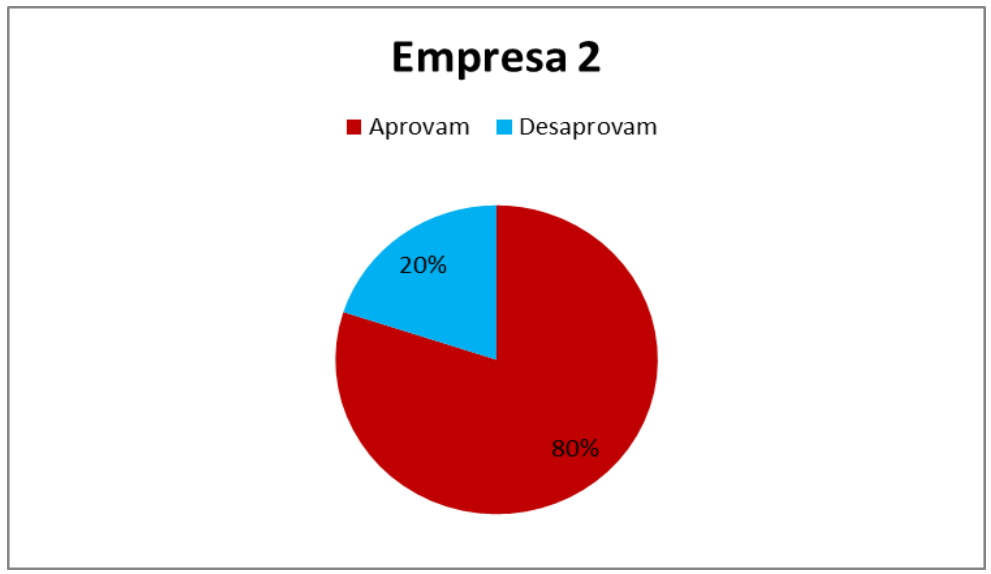


Fonte: Dados da pesquisa.

E como último item analisado, foram elencados os percentuais de funcionários dispostos ou não a execução de atividades relacionadas à educação corporativa, conforme dados ilustrados na Figura 8. FIGURA 8 - DISPONIBILIDADE DE FUNCIONÁRIOS PARA QUALIFICAÇÃO EM EDUCAÇÃO
CORPORATIVA

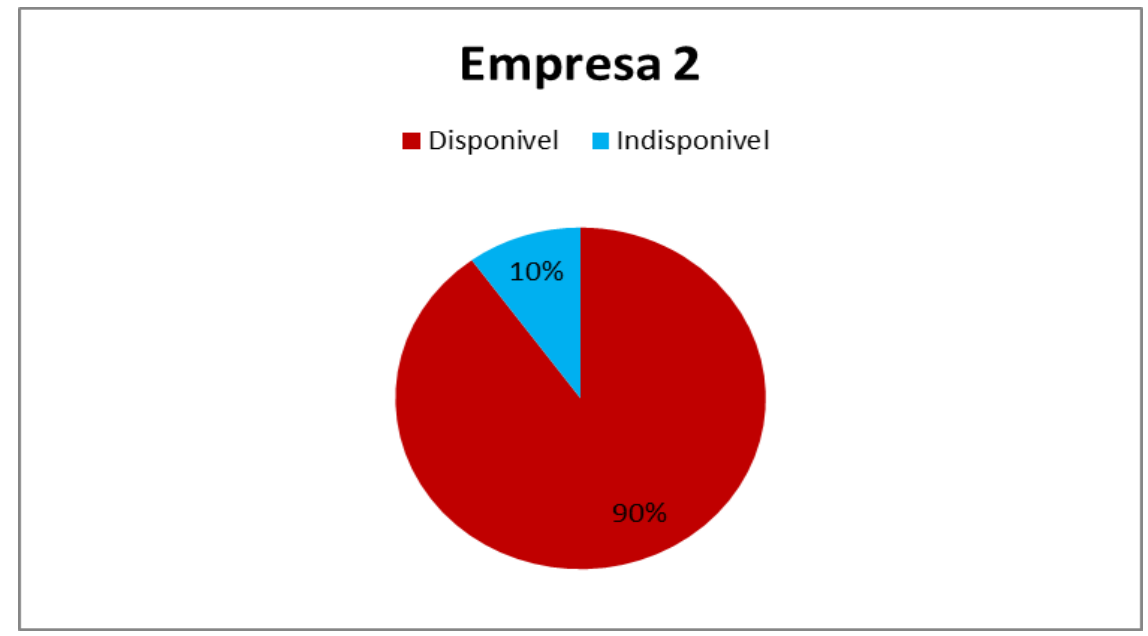

Fonte: Dados da pesquisa.

Neste caso, pode-se notar que houve uma disparidade entre a aprovação dos metodos de educação corporativa e sua disponibilidade, onde a disponibilidade dos funcionários da Empresa 2 tende a ser maior do que os niveis de aprovação, assim indicando um nível maior de interesse dos funcionários.

\section{Empresa 3}

Para os dados analisados da Empresa 3, obteve-se os seguintes resultados referentes a participação entre os setores, conforme Figura 9.

FIGURA 9 - PESQUISAS APLICADAS POR SETOR DA EMPRESA

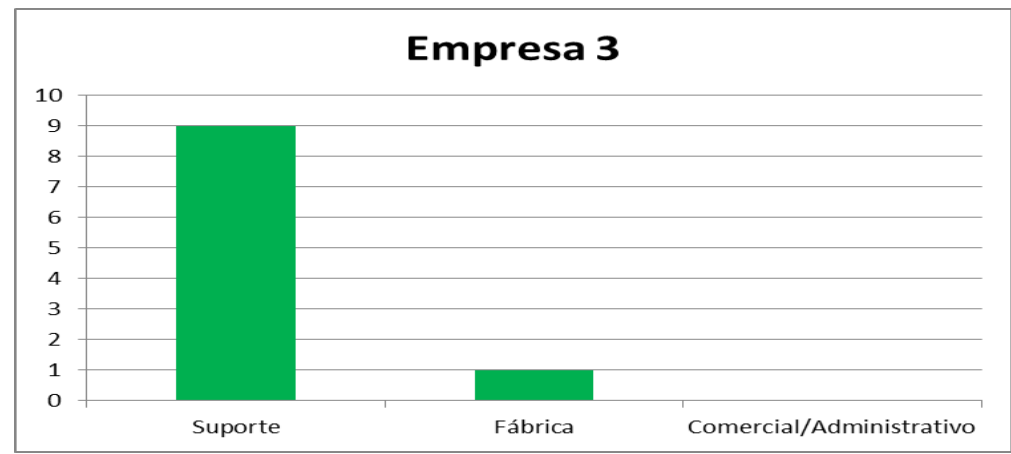


Fonte: Dados da pesquisa.

Neste caso, observa-se a inexistência da participação de setores como administrativo e comercial, sendo somente amostradas nos setores de suporte ( 9 amostras) e fábrica ( 1 amostra). Na Figura 10 está o nível de satisfação encontrado para a Empresa 3, onde existe uma equiparação nos níveis de satisfação dos funcionários satisfeitos e muito satisfeitos, com 3 amostras cada e 4 amostras para os funcionários insatisfeitos.

FIGURA 10 - NÍVEL DE SATISFAÇÃO ENTRE OS ENTREVISTADOS

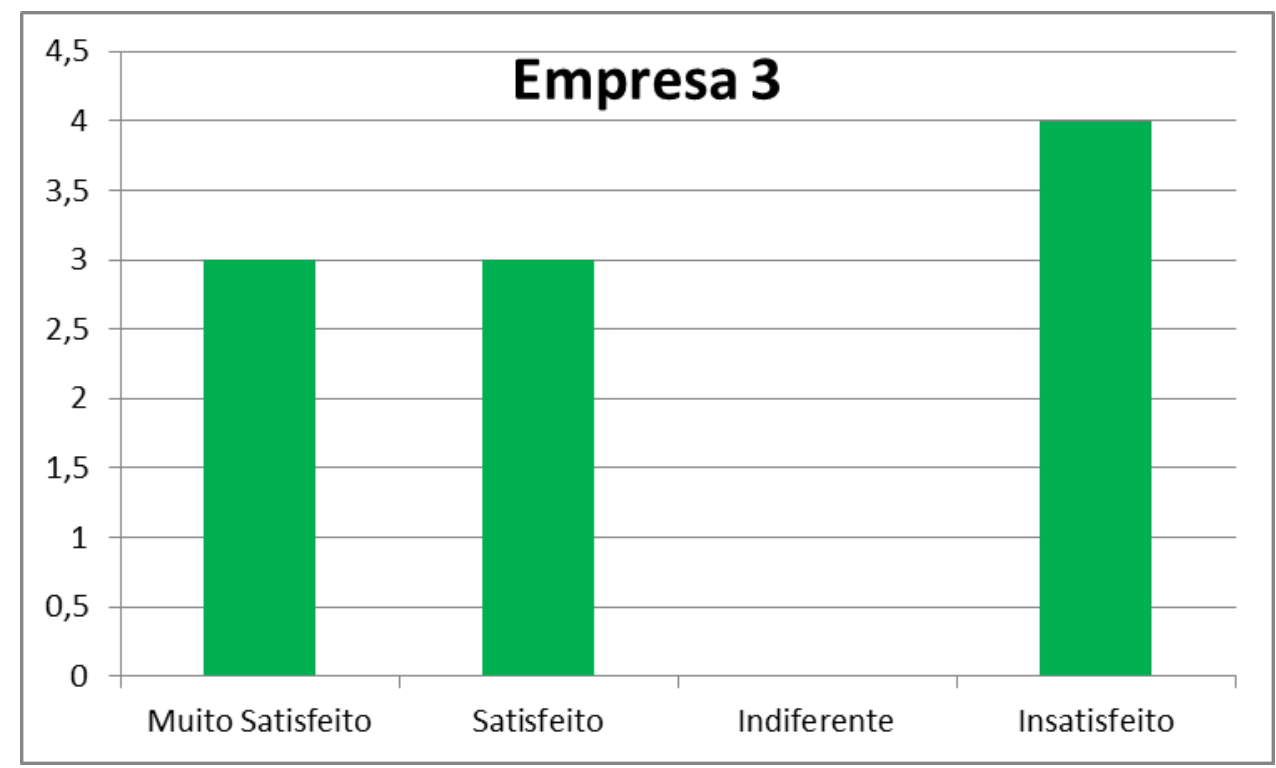

Fonte: Dados da pesquisa.

Ao analisar os dados da Figura 10 em um ambiente macro, pode-se analisar que o montante de funcionários satisfeitos cresce e se torna maior em comparação com os desaprovantes, conforme a Figura 11.

\section{GRÁFICO 11 - PERCENTUAIS DE APROVAÇÃO DA POLITICA DE EDUCAÇÃo CORPORATIVA}

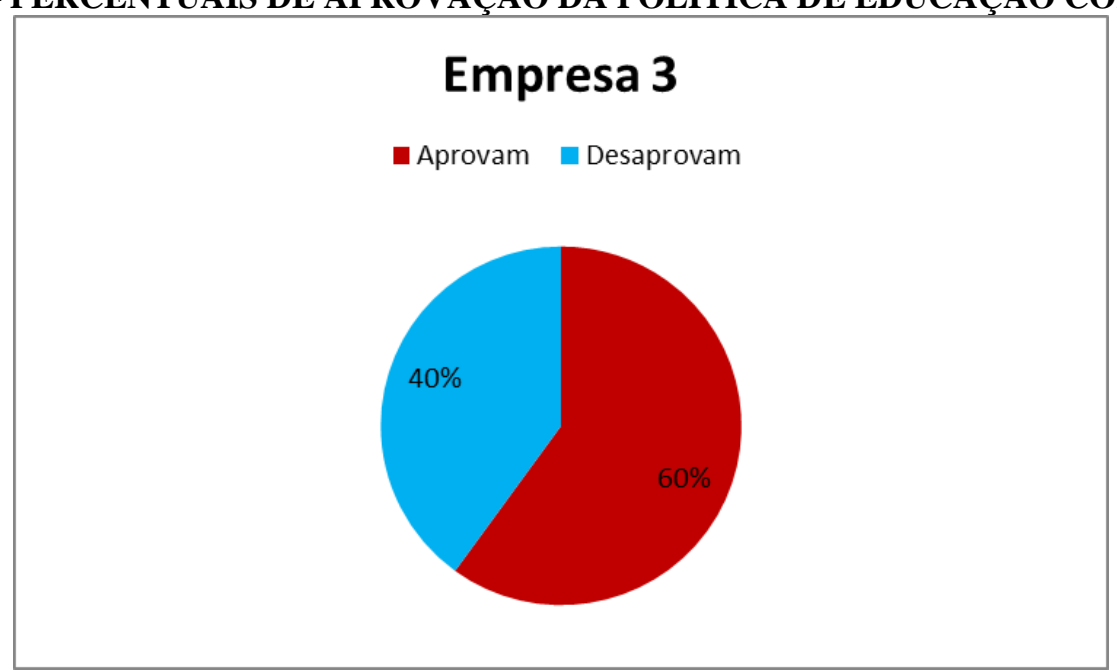


Fonte: Dados da pesquisa.

E por fim, ao analisar os dados de funcionários que estariam disponíveis para tais atividades, há uma equivalência às aprovações e desaprovações, onde os percentuais se mantém, conforme a Figura 12. FIGURA 12 - DISPONIBILIDADE DE FUNCIONÁRIOS PARA QUALIFICAÇÃO EM EDUCAÇÃO
CORPORATIVA

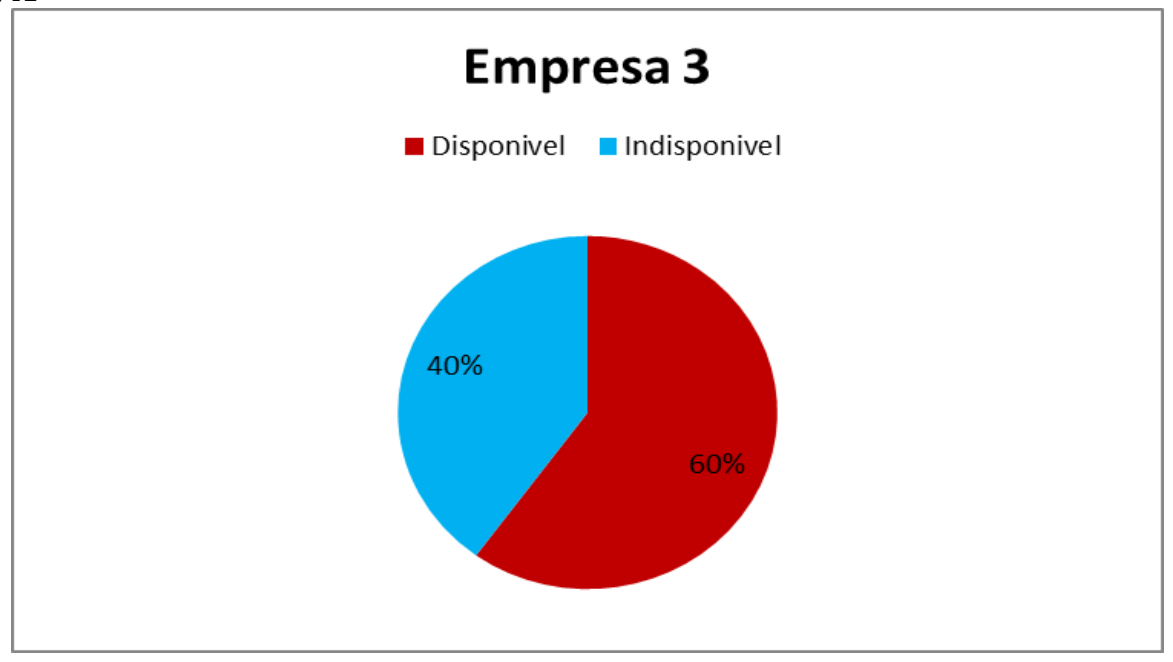

Fonte: Dados da pesquisa.

\section{Análise Geral}

Ao analisar os dados em âmbito geral das três empresas, juntando todas as amostras, pode-se validar que os níveis de insatisfação encontrado se tornam significativos oque inviabilizam as implementações de tais sistemas de educação corporativas nas empresas abordados, trazendo assim um ponto a se averiguar no processo instituído nas empresas.

$\mathrm{Na}$ Figura 13, podemos validar que os percentuais dos níveis de indiferença e insatisfação são significativos, conforme elencado anteriormente.

FIGURA 13 - MONTANTE DOS NÍVEIS DE SATISFAÇÃO 


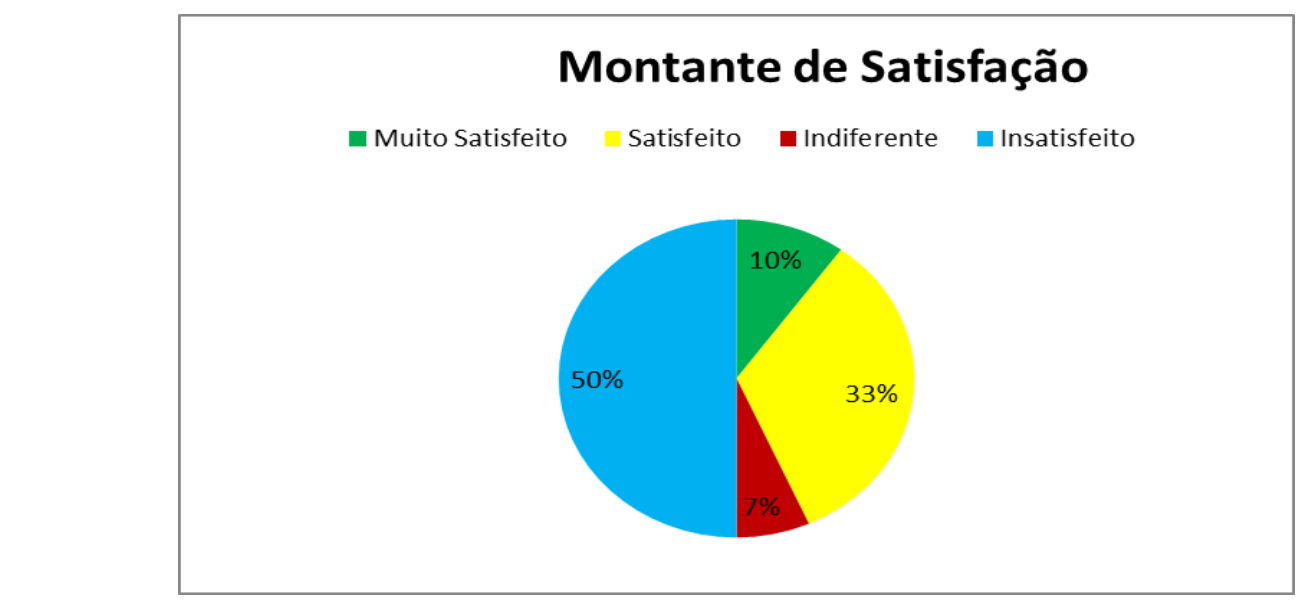

Fonte: Dados da pesquisa.

Com o montante de apenas $10 \%$, os funcionários muito satisfeitos com o processo de educação corporativa é tão pequeno ao ser comparado a insatisfação crescente de $50 \%$ dos demais funcionários, que mostram claramente a disparidade entre os níveis de satisfação.

\section{Pontos Analisados Livremente}

Após chegar em índices alarmantes sobre a implementação dos métodos de educação corporativa, foram analisados tambem os comentarios deixados de forma livre, em forma de pergunta, para que os mesmos funcionários pudessem responder. Com eles foi possivel criar uma visão mais coesa dos motivos que levaram os mesmos a estarem insatisfeitos com o processo adotado em um ambito geral das empresas abordadas.

Estão elencados a seguir alguns dos pontos citados pelos funcionários e que no ponto de vista dos mesmos, seriam as razões pelas quais as respostas estavam sendo elencadas em cada situação:

- Alta carga de trabalho normal e sobrecarga com as demais atividades propostas;

- Capacitações fora do contexto necessário;

- Sem motivação salarial para a execução das devidas atividades;

- Falta do conhecimento de tais propostas da empresa;

- Nivel de conhecimento dos professores inadequado;

- Problemas pessoais e extra empresarial.

Com estes pontos elencados pelos funcionários abordados, pode-se analisar que a insatisfação junto aos programas de educação corporativa esta muito interligada a motivação que o funcionário recebe para o executar, bem como o relacionamento interpessoal dentro e fora da empresa, assim levando as respostas para a devida insatisfação, conforme já explanado.

\section{Considerações Finais}


Dentre das empresas avaliadas, pôde-se ver que existe sim uma divergência entre as amostras, onde não há somente uma constância pela satisfação ou pela insatisfação, porém sempre com uma constância muito mais significativa de insatisfação.

A prática de educação corporativa nas empresas de software da cidade de Dois Vizinhos - PR se provou ser um ponto a ser reavaliado, principalmente os métodos de implementação e motivação para junto aos funcionários, para que desta forma possa alcançar um número maior de adeptos e além dessa adesão, um número maior ao que diz respeito a satisfação encontrada junto aos colaboradores.

\section{Referências}

CASALETTI, B. EDUCAÇÃO CORPORATIVA: um tema da contemporaneidade. Rio Grande do Sul, 2013 - $\quad$ Acessado em 28/07/2017 em http://www.periodicos.ufpb.br/ojs/index.php/mpgoa/article/view/16788/9732.

CRUZ, D. EDUCAÇÃO CORPORATIVA: A PROPOSTA EMPRESARIAL NO DISCURSO E NA PRÁTICA. - $\quad$ Acessado em 28/07/2017 em http://www.scielo.br/pdf/edur/v26n2/a16v26n2.

ÉBOLI, Marisa. Educação Corporativa no Brasil: Da Prática à Teoria. São Paulo, 2004 Acessado em 28/07/2017 em http://www.anpad.org.br/admin/pdf/enanpad2004-grt-1816.pdf.

ESTEVES, L. A EDUCAÇÃo CORPORATIVA E A GESTÃo dO CONHECIMENTO. Acessado em 28/07/2017 em http://www.inovarse.org/sites/default/files/T_15_042M.pdf.

MEISTER, J. C. Educação corporativa: a gestão do capital intelectual por meio das universidades corporativas. São Paulo: Makron Books, 1999.

TENÓRIO, R. GESTÃO NA EDUCAÇÃO: DA "POLÍTICA" DE ARISTÓTELES À EDUCAÇÃO CORPORATIVA - Acessado em 28/07/2017

http://www.anpae.org.br/congressos_antigos/simposio2007/383.pdf 